\title{
DEVELOPMENT OF A MULTICOMPONENT PREDICTION MODEL FOR ACUTE ESOPHAGITIS IN LUNG CANCER PATIENTS RECEIVING CHEMORADIOTHERAPY
}

Citation for published version (APA):

De Ruyck, K., Sabbe, N., Oberije, C., Vandecasteele, K., Thas, O., De Ruysscher, D., Lambin, P., Van Meerbeeck, J., De Neve, W., \& Thierens, H. (2011). DEVELOPMENT OF A MULTICOMPONENT PREDICTION MODEL FOR ACUTE ESOPHAGITIS IN LUNG CANCER PATIENTS RECEIVING CHEMORADIOTHERAPY. International Journal of Radiation Oncology Biology Physics, 81(2), 537-544. https://doi.org/10.1016/j.jirobp.2011.03.012

Document status and date:

Published: 01/10/2011

DOI:

10.1016/j.jijrobp.2011.03.012

Document Version:

Publisher's PDF, also known as Version of record

\section{Document license:}

Taverne

\section{Please check the document version of this publication:}

- A submitted manuscript is the version of the article upon submission and before peer-review. There can be important differences between the submitted version and the official published version of record. People interested in the research are advised to contact the author for the final version of the publication, or visit the DOI to the publisher's website.

- The final author version and the galley proof are versions of the publication after peer review.

- The final published version features the final layout of the paper including the volume, issue and page numbers.

Link to publication

\footnotetext{
General rights rights.

- You may freely distribute the URL identifying the publication in the public portal. please follow below link for the End User Agreement:

www.umlib.nl/taverne-license

Take down policy

If you believe that this document breaches copyright please contact us at:

repository@maastrichtuniversity.nl

providing details and we will investigate your claim.
}

Copyright and moral rights for the publications made accessible in the public portal are retained by the authors and/or other copyright owners and it is a condition of accessing publications that users recognise and abide by the legal requirements associated with these

- Users may download and print one copy of any publication from the public portal for the purpose of private study or research.

- You may not further distribute the material or use it for any profit-making activity or commercial gain

If the publication is distributed under the terms of Article 25fa of the Dutch Copyright Act, indicated by the "Taverne" license above, 


\title{
DEVELOPMENT OF A MULTICOMPONENT PREDICTION MODEL FOR ACUTE ESOPHAGITIS IN LUNG CANCER PATIENTS RECEIVING CHEMORADIOTHERAPY
}

\author{
Kim De Ruyck, Ph.D., ${ }^{*}$ Nick Sabbe, M.Sc., ${ }^{\dagger}$ Cary Oberije, Ph.D., ${ }^{\ddagger}$ Katrien Vandecasteele, M.D. ${ }^{\S}$ \\ Olivier Thas, Ph.D., ${ }^{\dagger}$ Dirk De Ruysscher, M.D., Ph.D., ${ }^{\ddagger}$ Phillipe Lambin, M.D., Ph.D. ${ }^{\ddagger}$ \\ Jan Van Meerbeeck, M.D., Ph.D.,"Wilfried De Neve, M.D., Ph.D., ${ }^{\S}$ and Hubert Thierens, Ph.D.* \\ Departments of *Basic Medical Sciences and ${ }^{\dagger}$ Applied Mathematics, Biometrics and Process Control, Ghent University, Ghent, \\ Belgium; ${ }^{\ddagger}$ Department of Radiation Oncology (MAASTRO Clinic), Research Institute of Growth and Development, Maastricht \\ University Medical Center, Maastricht, The Netherlands; and Departments of ${ }^{\S}$ Radiation Oncology and ${ }^{\|}$Respiratory Medicine, Ghent \\ University Hospital, Ghent, Belgium
}

\begin{abstract}
Purpose: To construct a model for the prediction of acute esophagitis in lung cancer patients receiving chemoradiotherapy by combining clinical data, treatment parameters, and genotyping profile.

Patients and Methods: Data were available for 273 lung cancer patients treated with curative chemoradiotherapy. Clinical data included gender, age, World Health Organization performance score, nicotine use, diabetes, chronic disease, tumor type, tumor stage, lymph node stage, tumor location, and medical center. Treatment parameters included chemotherapy, surgery, radiotherapy technique, tumor dose, mean fractionation size, mean and maximal esophageal dose, and overall treatment time. A total of 332 genetic polymorphisms were considered in 112 candidate genes. The predicting model was achieved by lasso logistic regression for predictor selection, followed by classic logistic regression for unbiased estimation of the coefficients. Performance of the model was expressed as the area under the curve of the receiver operating characteristic and as the false-negative rate in the optimal point on the receiver operating characteristic curve.

Results: A total of 110 patients $(\mathbf{4 0 \%})$ developed acute esophagitis Grade $\geq 2$ (Common Terminology Criteria for Adverse Events v3.0). The final model contained chemotherapy treatment, lymph node stage, mean esophageal dose, gender, overall treatment time, radiotherapy technique, rs2302535 (EGFR), rs16930129 (ENG), rs1131877 (TRAF3), and rs2230528 (ITGB2). The area under the curve was 0.87 , and the false-negative rate was $16 \%$.

Conclusion: Prediction of acute esophagitis can be improved by combining clinical, treatment, and genetic factors. A multicomponent prediction model for acute esophagitis with a sensitivity of $84 \%$ was constructed with two clin-

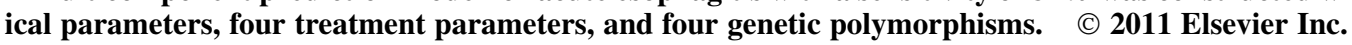

Prediction, Esophagitis, Radiotherapy, Genetic polymorphisms, Lasso logistic regression.

\section{INTRODUCTION}

Lung cancer has the highest incidence and mortality rate of all cancers in Western countries, with most patients presenting with advanced-stage disease at the time of diagnosis (1). The standard of care for locally advanced non-small-cell lung cancer is concurrent chemoradiotherapy. Treatment success is, however, still constrained by poor local control and posttherapy toxicity as acute esophagitis $(2,3)$.

Numerous studies have attempted to define clinical and dosimetric predictors of radiation-induced esophagitis (4-21). Factors found to correlate with important acute esophagitis include concurrent chemoradiotherapy, lymphatic status, and a number of dose-volumetric parameters. Because the results varied considerably across different institutions, their clinical usefulness remains restricted. Simultaneously, significant research efforts have been made to link genetic polymorphisms in selected genes to radiation-induced toxicity (22-30). The majority of these radiogenetics studies considered patients with breast or prostate cancer, whereas only a few research groups reported on radiation-induced toxicity after radiotherapy for lung cancer (28-31). Because of the limited genetic studies performed for esophagitis and the inconsistent outcomes for other radiation-induced toxicities, genetic biomarkers are not yet implementable in the clinic.
Reprint requests to: Kim De Ruyck, Ph.D., Ghent University, Department of Basic Medical Sciences, Proeftuinstraat 86, B-9000 Ghent, Belgium. Tel: (+32)-926-46656; Fax: (+32) 92646696; E-mail: kim.deruyck@UGent.be

Supported by Grant No. 365D6706 from the Stichting tegen Kanker and Grant No. 09/PDO/061 from the Fonds voor Wetenschappelijk Onderzoek.
Conflicts of interest: none.

Acknowledgments-The authors thank all the study participants and data managers, Dr. Bart Loeys, and Virginie de Gelder.

Received Jan 25, 2011, Accepted for publication March 8, 2011. 
Over the years it has become clear that the effects of dose distribution, clinical parameters, and individual genetic variation on radiation-induced toxicity may not be evaluated separately. As a result, studies are emerging that correct for dosimetric and patient-related risk factors when trying to link genetic polymorphisms with a clinical phenotype after therapy (29, 31-34). However, a model to predict susceptibility to radiation in individual patients is still unavailable. Therefore, we aimed at constructing a predictive algorithm for acute esophagitis by combining clinical data, treatment parameters, and genotypic information. This would enable us to individualize patient treatment.

\section{PATIENTS AND METHODS}

\section{Study population}

Two hundred eighty-nine lung cancer patients treated with curative radiotherapy between February 2004 and August 2009 were enrolled. Of these, 273 were suited to perform the study (Fig. 1). A total of 213 patients were recruited from the MAASTRO Clinic and 60 patients from the Ghent University Hospital. Clinical data and treatment details are presented in Table 1 . The majority of patients were treated with three-dimensional conformal radiotherapy (3D-CRT) as opposed to intensity-modulated radiotherapy (IMRT). The median tumor dose was $60 \mathrm{~Gy}$ at $1.5-2.69 \mathrm{~Gy}$ per fraction ( 2 patients received 7.5 Gy per fraction). The details of the different radiotherapy treatment regimens can be found in Appendix E1 (available online). For the MAASTRO Clinic patients, the dosimetric parameters were calculated using a commercial radiotherapy treatment planning system (XiO; Computerized Medical Systems, St. Louis, MO). The dosimetric parameters for the Ghent patients were calculated using an in-house-developed planning system, with a final dose computation using a commercial radiotherapy planning system (Pinnacle; Philips Medical Systems, Best, The Netherlands). In both centers, the esophagus was delineated using the external esophageal contour from the cricoid cartilage to the gastroesophageal junction. Esophageal toxicity was scored

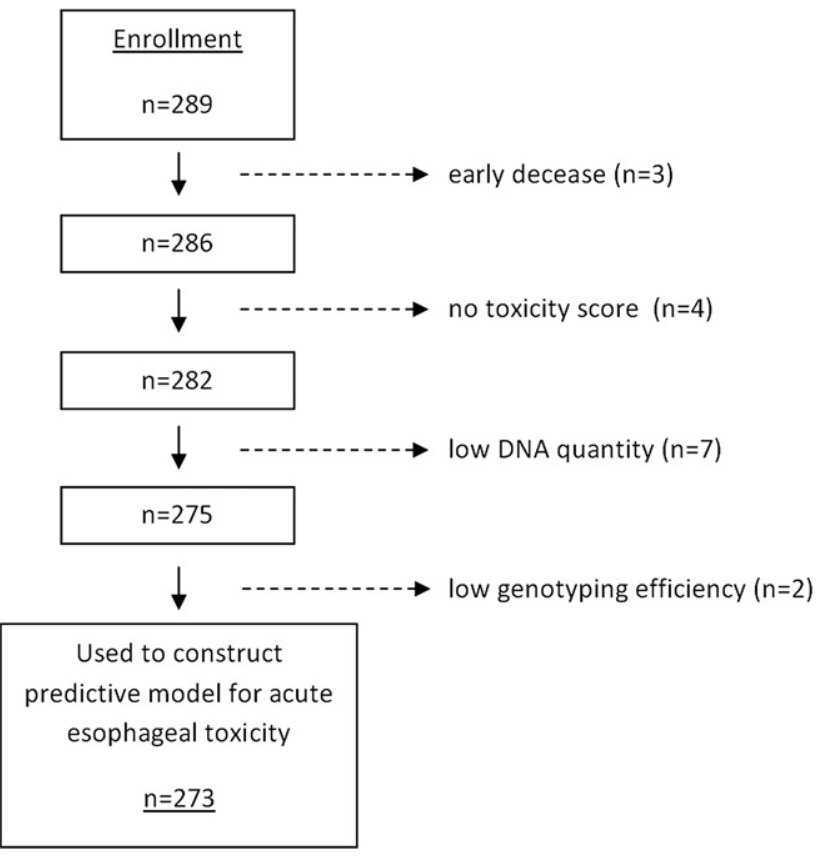

Fig. Study flowchart. using the Common Terminology Criteria for Adverse Events scale version 3.0 (35). Acute esophagitis was defined as dysphagia Grade $\geq 2$ at any time during or at maximum 3 months after radiotherapy treatment. Genomic DNA was obtained from fresh blood (Ghent samples) or frozen buffy coat (MAASTRO samples) using the Puregene genomic DNA purification kit (Gentra Systems, Minneapolis, MN). The study was approved by the ethics committees of both centers, and all study participants provided written informed consent. The MAASTRO Clinic cohort study was filed at clinicaltrials.gov (no. NCT01084785).

\section{Selection of candidate genes and genetic variations}

On the basis of a literature search, a total of 112 candidate genes belonging to the following categories were considered: early response genes $(n=15)$, cytokines and growth factors $(n=14)$, signal transduction of cytokines and growth factors $(n=53)$, adhesion molecules $(n=9)$, extracellular matrix genes $(n=13)$, and others $(n=8)$. Single nucleotide polymorphisms (SNPs) were selected after functional tagging based on evolutionary conserved regions (ECRs) using ECR Browser (36). The $5^{\prime}$ flanking region of each gene $(5 \mathrm{~kb})$ was included to thoroughly examine any possible regulatory regions. Conserved regions with a minimal length of $100 \mathrm{bp}$ with minimal $80 \%$ equality over four species (mouse, rat, rhesus monkey, and human) were considered. The criteria for picking SNPs in the ECRs were as follows: minor allele frequencies in populations of Caucasian ethnicity $>5 \%$, Illumina SNP score $>0.60$ (proprietary score used to determine the overall success of the assay), and no linkage $\left(r^{2}>0.80\right)$ with other SNPs. Lessstringent criteria were used for cytokines, their receptors, and cell adhesion molecules (ECRs of 75\% equality over three species). The selection was expanded with a number of SNPs with a proven biological function from the literature. Finally, 384 SNPs were retained (Table E1).

\section{Genotyping and quality control}

The DNA quality and quantity were checked before genotyping, and 7 individuals were omitted from genotyping because of low DNA quantity. Genotyping was performed using the Illumina Goldengate technology (DNA Vision, Charleroi, Belgium). Upon completion of genotyping, quality control (QC) processes were run to guarantee the accuracy of the genotyped dataset. Two individuals were dropped on the basis of low genotyping efficiency $(<90 \%)$. Single nucleotide polymorphisms were eliminated on the basis of low reliability of cluster separation, low signal intensity, low call frequency $(<75 \%)$, absence of a minor allele in the dataset, and deviation from Hardy-Weinberg equilibrium $(p<0.0001)$. After application of stringent $\mathrm{QC}$, approximately $3 \%$ of the samples and approximately $13 \%$ of the SNPs were eliminated. Overall, QC was completed yielding 273 individuals and 332 SNPs (Table E1).

\section{Statistics}

The predicting model was achieved in two steps. First, lasso logistic regression was applied to the full dataset, for which the lasso parameter was chosen so as to maximize the area under the curve (AUC) of the receiver operator characteristic (ROC) curve. The latter was estimated from 10-fold cross-validation (37). Second, the implied set of predictors was passed to classic logistic regression for unbiased estimation of the coefficients.

Lasso regression shrinks the coefficient estimates toward zero, with the degree of shrinkage depending on an additional parameter, lambda $(\lambda)$. In this way, coefficient estimates can be forced to be exactly zero, thereby effectively eliminating a number of variables. 
Table 1. Clinical and treatment parameters for esophageal toxicity

\begin{tabular}{|c|c|c|c|}
\hline Parameter & All $(n=273)$ & Grade $0-1(n=163)$ & Grade $2+(n=110)$ \\
\hline \multicolumn{4}{|l|}{ Clinical parameters } \\
\hline \multicolumn{4}{|l|}{ Gender $(n)$} \\
\hline Men & $200(73.3)$ & $136(83.4)$ & $64(58.2)$ \\
\hline Woman & $73(26.7)$ & $27(16.6)$ & $46(41.8)$ \\
\hline \multicolumn{4}{|l|}{ Age $(y)$} \\
\hline Median & 66.6 & 68.5 & 61.5 \\
\hline Range & $42.8-87.0$ & $44.0-87.0$ & $42.8-86.0$ \\
\hline \multicolumn{4}{|l|}{ WHO performance score $(n)$} \\
\hline 0 & $88(32.2)$ & $53(32.5)$ & $35(31.8)$ \\
\hline 1 & $144(52.7)$ & $84(51.5)$ & $60(54.5)$ \\
\hline$\geq 2$ & $39(14.3)$ & $25(15.3)$ & $14(12.7)$ \\
\hline Missing & $2(0.7)$ & $1(0.6)$ & $1(0.9)$ \\
\hline \multicolumn{4}{|l|}{ Nicotine use $(n)$} \\
\hline Never & $7(2.6)$ & $4(2.5)$ & $3(2.7)$ \\
\hline Current & $93(34.1)$ & 48 (29.4) & $45(40.9)$ \\
\hline Former & $165(60.4)$ & $107(65.6)$ & $58(52.7)$ \\
\hline Missing & $8(2.9)$ & $4(2.5)$ & $4(3.6)$ \\
\hline \multicolumn{4}{|l|}{ Diabetes $(n)$} \\
\hline Yes & $23(8.4)$ & $18(11.0)$ & $5(4.5)$ \\
\hline No & $231(84.6)$ & $141(86.5)$ & $90(81.8)$ \\
\hline Missing & $19(7.0)$ & $4(2.5)$ & 15 (13.6) \\
\hline \multicolumn{4}{|l|}{ Chronic disease* $(n)$} \\
\hline Yes & $7(2.6)$ & $3(1.8)$ & $4(3.6)$ \\
\hline No & $250(91.6)$ & $154(94.5)$ & $96(87.3)$ \\
\hline Missing & $16(5.9)$ & $6(3.7)$ & $10(9.1)$ \\
\hline \multicolumn{4}{|l|}{ Tumor type $(n)$} \\
\hline NSCLC & 209 (76.6) & $135(82.8)$ & $74(67.3)$ \\
\hline SCLC & $50(18.3)$ & $17(10.4)$ & $33(30.0)$ \\
\hline Missing & $14(5.1)$ & $11(6.7)$ & $3(2.7)$ \\
\hline \multicolumn{4}{|l|}{ Tumor stage $(n)$} \\
\hline I & $40(14.7)$ & $36(22.1)$ & $4(3.6)$ \\
\hline II & $27(9.9)$ & $19(11.7)$ & $8(7.3)$ \\
\hline IIIa & $88(32.2)$ & $59(36.2)$ & $29(26.4)$ \\
\hline IIIb & $102(37.4)$ & $43(26.4)$ & $59(53.6)$ \\
\hline IV & $5(1.8)$ & $1(0.6)$ & $4(3.6)$ \\
\hline Missing & $11(4.0)$ & $5(3.1)$ & $6(5.5)$ \\
\hline \multicolumn{4}{|l|}{ Lymph node stage $(n)$} \\
\hline No & $83(30.4)$ & $67(41.1)$ & $16(14.5)$ \\
\hline N1 & $20(7.3)$ & $15(9.2)$ & $5(4.5)$ \\
\hline $\mathrm{N} 2$ & $95(34.8)$ & $58(35.6)$ & 37 (33.6) \\
\hline N3 & $64(23.4)$ & $18(11.0)$ & $46(41.8)$ \\
\hline Missing & $11(4.0)$ & $5(3.1)$ & $6(5.5)$ \\
\hline \multicolumn{4}{|l|}{ Tumor location $(n)$} \\
\hline Lower lobe & $61(22.3)$ & $34(20.9)$ & $27(24.5)$ \\
\hline Other & $200(73.3)$ & $123(75.5)$ & $77(70.0)$ \\
\hline Missing & $12(4.4)$ & $6(3.7)$ & $6(5.5)$ \\
\hline \multicolumn{4}{|l|}{ Medical center $(n)$} \\
\hline Ghent University Hospital & $60(22.0)$ & $46(28.2)$ & 14 (12.7) \\
\hline MAASTRO Clinic & $213(78.0)$ & $117(71.8)$ & $96(87.3)$ \\
\hline \multicolumn{4}{|l|}{ Treatment parameters } \\
\hline \multicolumn{4}{|l|}{ Chemotherapy $(n)$} \\
\hline No & $69(25.3)$ & $55(33.7)$ & $14(12.7)$ \\
\hline Sequential & $120(44.0)$ & $83(50.9)$ & 37 (33.6) \\
\hline Concurrent & $84(30.8)$ & $25(15.3)$ & $59(53.6)$ \\
\hline \multicolumn{4}{|l|}{ Surgery $(n)$} \\
\hline Yes & $35(12.8)$ & $25(15.3)$ & $10(9.1)$ \\
\hline No & $238(87.2)$ & $138(84.7)$ & $100(90.9)$ \\
\hline Radiotherapy technique $(n)$ & & & \\
\hline 3D-CRT & $224(82.1)$ & $124(76.1)$ & $100(90.9)$ \\
\hline IMRT & 49 (17.9) & $39(23.9)$ & $10(9.1)$ \\
\hline Tumor dose (Gy) & & & \\
\hline Median & 60.0 & 64.0 & 54.0 \\
\hline Range & $40.0-79.2$ & $40.0-79.2$ & $\begin{array}{l}\text { 45.0-79.2 } \\
\quad \text { (Continued })\end{array}$ \\
\hline
\end{tabular}


Table 1. Clinical and treatment parameters for esophageal toxicity (Continued)

\begin{tabular}{|c|c|c|c|}
\hline Parameter & All $(n=273)$ & Grade $0-1(n=163)$ & Grade $2+(n=110)$ \\
\hline \multicolumn{4}{|c|}{ Mean fractionation size (Gy) } \\
\hline Median & 1.8 & 1.8 & 1.8 \\
\hline \multicolumn{4}{|c|}{ Mean esophageal dose (Gy) } \\
\hline Median & 21.7 & 16.3 & 26.1 \\
\hline Range & $0.4-45.7$ & $0.4-41.9$ & $3.5-45.7$ \\
\hline \multicolumn{4}{|c|}{ Maximum esophageal dose (Gy) } \\
\hline Median & 56.3 & 56.0 & 56.5 \\
\hline Range & $1.1-84.2$ & $1.1-81.8$ & $22.8-84.2$ \\
\hline Missing & 22 & 14 & 8 \\
\hline \multicolumn{4}{|c|}{ Overall treatment time $(\mathrm{d})$} \\
\hline Median & 31.0 & 36.0 & 25.0 \\
\hline Range & $17.0-62.0$ & $17.0-62.0$ & $19.0-61.0$ \\
\hline
\end{tabular}

Abbreviations: $\mathrm{WHO}=$ World Health Organization; NSCLC $=$ non-small-cell lung cancer; 3D-CRT = three-dimensional conformal radiotherapy; IMRT = intensity-modulated radiotherapy.

Data in parentheses are percentages.

* Gastroesophageal reflux disease, Barrett's syndrome, previous larynx carcinoma.

By varying $\lambda$ from 0 to 1 , and, for each value of $\lambda$, evaluating a measure of predictive value (AUC) by cross-validation, the optimal $\lambda$ is found. This choice of $\lambda$ corresponds to a fitted lasso regression model for which a limited set of variables provides an acceptable level of predictive stability, whereas adding more variables does not increase the predictive value. As a result, a set of predictors is obtained for the selected $\lambda$ value (i.e., the lasso step acts as a model selection procedure). A consequence of the lasso technique is that all coefficient estimates tend to be downwardly biased. Therefore in a second step, a classic non-lasso logistic regression was performed to find unbiased estimates of the coefficients of the selected set of predictors. Again, the predictive value was evaluated through 10- fold cross-validation. The problem of missing values was surmounted by applying multiple imputation (38-40). For each step described above, 500 full datasets were imputed using predictive mean matching for continuous variables and polytomous logistic regression for categoric variables. The analysis was applied to each of these full datasets, after which the results were averaged and the variances of the coefficient estimates were corrected for the variability added by the imputation. Because the AUC reflects the full spectrum of misclassification, it is only partially suited in this study, because our interest goes particularly to the part of the ROC curve where false negatives are unlikely. To this end, a criterion for a balanced "optimal point" on the ROC curve was

Table 2. Outcome of modeling analyses

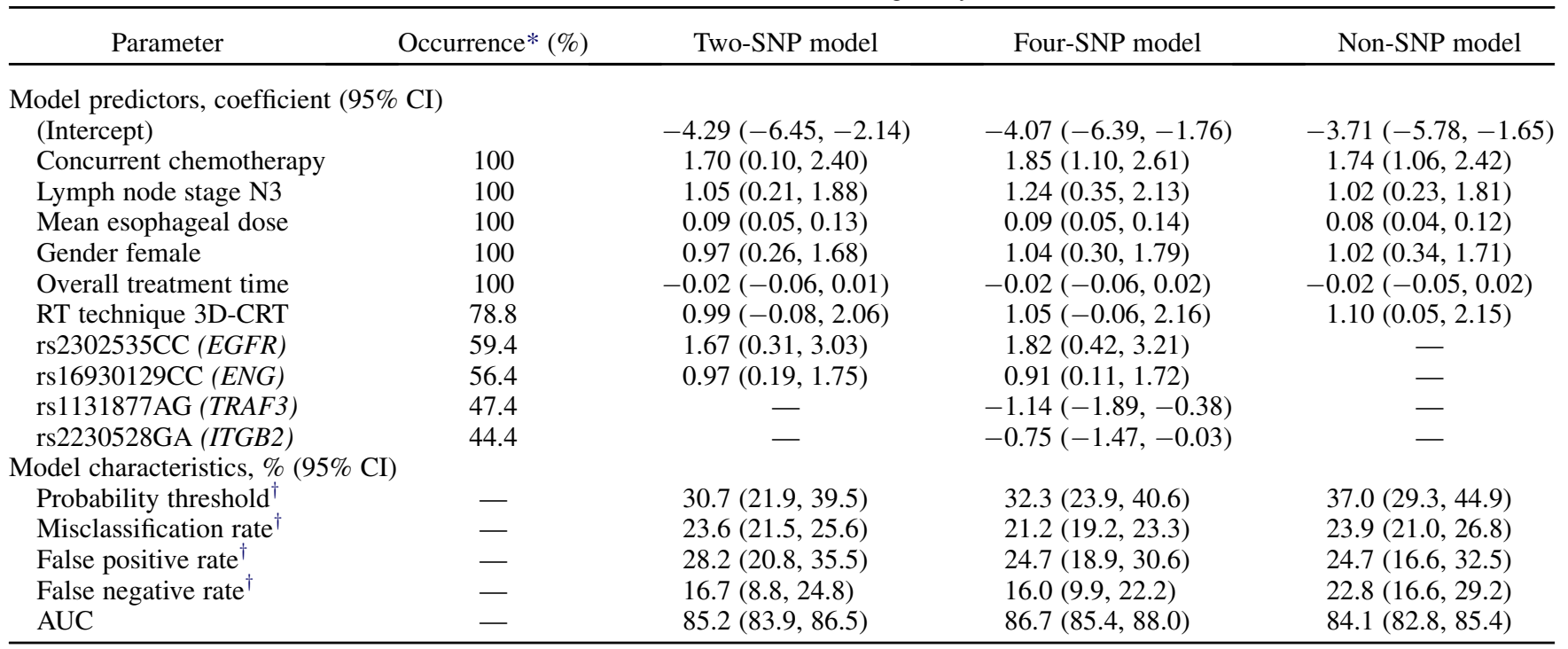

Abbreviations: $\mathrm{SNP}=$ single nucleotide polymorphism; CI = confidence interval; RT = radiotherapy; $3 \mathrm{D}-\mathrm{CRT}=$ three-dimensional conformal RT; $\mathrm{AUC}=$ area under the curve.

Model expression: $\ln p /(1-p)=\beta_{0}+\beta_{1} \times \mathrm{x}_{1}+\beta_{2} \times \mathrm{x}_{2}+\beta_{3} \times \mathrm{x}_{3}+\beta_{4} \times \mathrm{x}_{4}+\beta_{5} \times \mathrm{x}_{5}+\beta_{6} \times \mathrm{x}_{6}+\ldots$ with $p=$ probability to develop acute esophagitis, $\beta=$ coefficient, $\mathrm{x}=$ variable/predictor, and $\mathrm{e}^{\beta 1}=$ increase in odds for predictor 1 (in the case of continuous variables: for an increase of the predictor by 1 unit) when the other predictors remain unchanged.

* Over all imputations and partial fits, how often is the predictor included in the best selected model?

${ }^{\dagger}$ In the optimal point on the receiver operator characteristic curve. 
used: false negatives received a relative weight of 1.5 while minimizing the distance to the perfect point of the ROC curve (top left). This resulted in a threshold for the prediction decision rule, as well as estimates for the false-negative and false-positive rates. The confidence intervals $(\mathrm{CI})$ of the coefficients are the ordinary logistic regression CIs, corrected for multiple imputation. All analyses were performed in $\mathrm{R}$ by applying the $\mathrm{R}$ package glmnet (41) for lasso regression and the R package MICE (42) for multiple imputation.

\section{RESULTS}

In total, 351 variables were available for model building. The 19 clinical/treatment parameters are listed in Table 1, and the 332 genetic polymorphisms are available in Table E1. After the variable selection procedure including all variables that occur in more than $50 \%$ of the imputed datasets, the model contained chemotherapy, lymph node stage, mean esophageal dose (MED), gender, overall treatment time (OTT), radiation technique, rs2302535, and rs16930129 (Table 2). Lowering the variable selection threshold to $40 \%$ resulted in the addition of the rs 1131877 and rs2230528 SNPs to the model (Table 2). Estimation of the predictor coefficients showed that, for both approaches, the most powerful risk predictors were concurrent chemotherapy and the rs2302535CC genotype. The AUCs of the two-SNPs model and the four-SNPs model were 0.85 and 0.87 , respectively. The false-negative rate in the optimal point of the ROC curve was slightly smaller for the model including four SNPs (16.0\% vs. 16.7\%). Analogous to the representation of the clinical/treatment variables in Table 1, the data for the four SNPs included in the models are presented in Table 3. Predictor coefficients and model characteristics were also estimated for a model excluding genetic

Table 3. Data for SNPs included in models

\begin{tabular}{lccc}
\hline \multicolumn{1}{c}{$\begin{array}{c}\text { All } \\
\text { SNP }\end{array}$} & $\begin{array}{c}\text { Grade } 0-1 \\
(n=273)\end{array}$ & $\begin{array}{c}\text { Grade 2+ } \\
(n=110)\end{array}$ \\
\hline rs2302535 $(E G F R)$ & & & \\
AA & $133(48.7)$ & $87(53.4)$ & $46(41.8)$ \\
AC & $121(44.3)$ & $71(43.6)$ & $50(45.5)$ \\
CC & $19(7.0)$ & $5(3.1)$ & $14(12.7)$ \\
Missing & 0 & 0 & 0 \\
rs16930129 $(E N G)$ & & & \\
CC & $207(75.8)$ & $114(69.9)$ & $93(84.5)$ \\
CT & $64(23.4)$ & $47(28.8)$ & $17(15.5)$ \\
TT & $2(0.7)$ & $2(1.2)$ & $0(0.0)$ \\
Missing & 0 & 0 & 0 \\
rs1131877 $($ TRAF3) & & & \\
AA & $164(60.3)$ & $92(56.4)$ & $72(66.1)$ \\
AG & $95(34.9)$ & $65(39.9)$ & $30(27.5)$ \\
GG & $13(4.8)$ & $6(3.7)$ & $7(6.4)$ \\
Missing & 1 & 0 & 1 \\
rs2230528 $(I T G B 2)$ & & & \\
GG & $151(55.7)$ & $82(50.6)$ & $69(63.3)$ \\
GA & $107(39.5)$ & $74(45.7)$ & $33(30.3)$ \\
AA & $13(4.8)$ & $6(3.7)$ & $7(6.4)$ \\
Missing & 2 & 1 & 1 \\
\hline
\end{tabular}

Abbreviation as in Table 2.

Data in parentheses are genotype frequencies. information. This non-SNP model had an AUC of 0.84 and a false-negative rate in the optimal point of the ROC curve of $22.8 \%$ (Table 2). The $95 \%$ CIs for the predictor coefficients are rather broad, whereas those for the measures of predictive value are relatively small. This indicates that the predictive accuracy using the given predictors and coefficients is stable.

\section{DISCUSSION}

Acute esophagitis is one of the most important side effects of high-dose radiotherapy for lung cancer, especially when combined with concurrent chemotherapy $(2,43)$. Currently, the prediction of this side effect is based on dosimetric parameters of radiotherapy only. However, these parameters lack sensitivity and specificity to estimate patient-specific treatment outcome correctly. To increase their predictive value, additional parameters are required. Different association studies point to the importance of the individual genotypic profile in therapy toxicity. Therefore, this study combined clinical data, treatment parameters, and genetic variation to develop a predictive multicomponent model for acute esophagitis. Single nucleotide polymorphisms in multispecies conserved sequences of candidate genes were considered. Conserved sequences have remained similar across the millions of years of evolution and are believed to indicate regions of biological function (44). By using conservation to prioritize SNPs, the chances may be increased that SNPs impacting phenotype will actually be genotyped. Including genetic variation data to model building may add to the model's predictive value but also complicates the analysis owing to the strong increase in the number of variables. To get around this problem, lasso logistic regression was applied because this technique finds models involving the smallest number of parameters while preserving predictive value. At the same time, variable inclusion is based on predictive value (as opposed to statistical significance) and over-/underfitting is avoided. In the present study, two clinical (lymph node stage and gender), four treatment (chemotherapy, MED, OTT, and radiation technique), and four genetic (rs2302535, rs 16930129, rs1131877, and rs2230528) parameters were found to be highly predictive for the development of Grade $\geq 2$ acute esophageal postradiotherapy toxicity.

Concurrent chemotherapy treatment has been accepted as a risk factor for acute esophagitis. In our study, in patients treated without or with concurrent chemotherapy, Grade $\geq 2$ acute esophagitis incidences were $27.0 \%$ and $70.2 \%$, respectively. This increase in toxicity for concurrent chemotherapy has also been found in a high number of other studies $(4,5,14,16,18-21)$. In parallel, published data demonstrate that the best-studied dosimetric parameters with high levels of association with acute esophagitis are MED, $\mathrm{V}_{20}, \mathrm{~V}_{30}$, $\mathrm{V}_{40}, \mathrm{~V}_{45}, \mathrm{~V}_{50}$, and $\mathrm{V}_{55}(4-6,8,9)$.

The predicting quality of lymph node stage could be explained by the correlation between the extent of lymph node involvement and the irradiated volume and dose to the 
esophagus, especially in patients with $\mathrm{N} 3$ disease (correlation coefficient with MED, 0.42). The median MED was 29.1 Gy for the N3 group, compared with 18.5 Gy for the N0/1/2 group. The incidence of Grade $\geq 2$ acute esophagitis was $71.9 \%$ in the $\mathrm{N} 3 \mathrm{arm}$, compared with $29.2 \%$ in the $\mathrm{N} 0 /$ $1 / 2 \mathrm{arm}$. These results generally agree with a number of other studies that found an association of nodal stage N2/ 3 with Grade $\geq 2$ acute esophagitis $(5,13-15)$. Although in previous studies gender was only exceptionally associated with acute esophagitis $(4,20)$, it was found to be a predictor in the present study. The incidence of Grade $\geq 2$ acute esophagitis was $63.0 \%$ for women and $32.0 \%$ for men.

Because of the use of different radiotherapy treatment regimens, treatment times varied considerably between patients, and treatment duration could be included in the analysis. As expected according to radiobiologic principles, short treatment times were found to be predictive for increased acute esophageal toxicity. This is in line with some $(4,20)$ but not all studies $(10,13)$. Compared with IMRT, 3D-CRT was predictive for acute esophagitis in the present study. This may be explained by the shorter treatment times for patients irradiated with 3D-CRT rather than by the dose to the esophagus (correlation coefficients of -0.52 and -0.09 , respectively). The median treatment time was 28 days for the 3D-CRT group and 47 days for the IMRT group, whereas the median MED was, respectively, 21.2 Gy and $26.1 \mathrm{~Gy}$. The incidence rate in the 3D-CRT arm was $44.6 \%$, compared with $20.4 \%$ in the IMRT arm. Alternatively, higher doses of radiation to parts of the esophagus outside of the planning target volumes, occurring more in 3D-CRT than in IMRT, may also explain the higher incidence of esophagitis in the 3D-CRT group.

The rs 2302535 SNP is situated in intron 2 of the epidermal growth factor receptor gene (EGFR). Epidermal growth factor receptor plays an important role in cellular signaling and is central to human tumorigenesis. Because in cancer cells the activation of EGFR leads to a series of intracellular signals resulting in increased tumor cell growth and resistance to apoptosis, EGFR inhibitors have found their use in anticancer treatment (45). In this context, EGFR polymorphisms are being studied in relation to disease response and toxicity after EGFR inhibitor therapy $(46,47)$. The rs16930129 SNP (Leu69Leu) is located in exon 2 of the endoglin gene $(E N G)$. Endoglin is a transforming growth factor (TGF) $\beta$ coreceptor mainly expressed in endothelial cells. It regulates cell proliferation and is important for endothelial cell survival and vessel repair. Mutations in endoglin have been linked to the vascular disease hereditary hemorrhagic telangiectasia, characterized by dilated capillaries (telangiectasia) that are prone to rupture (48). Radiation-induced vascular damage strongly resembles the symptoms of hereditary hemorrhagic telangiectasia patients, and animal studies showed an important role for endoglin in the development of radiation-induced normal tissue damage $(49,50)$. The rs1131877 SNP (Met129Thr) is situated in exon 3 of the tumor necrosis factor receptorassociated factor 3 gene (TRAF3). The encoded protein is a member of the TRAF family, which is important in activating multiple inflammatory and immune-related processes induced by cytokines such as tumor necrosis factor- $\alpha$ and interleukin-1 (51). The rs2230528 SNP (Gly273Gly) is part of exon 7 of the integrin $\beta 2$ gene (ITGB2). Integrin $\beta 2$ belongs to the integrin $\beta$-chain family proteins that may combine with $\alpha$-chain family proteins to form $\beta 2$ integrins. These $\beta 2$ integrins are leukocyte cell adhesion molecules including LFA-1 and Mac-1, with an important role in cell-surface-mediated signaling and radiation-mediated inflammation. It has been found that radiation induces changes in the expression of various integrins, with important implications for tumor control and normal tissue toxicity (52).

Generally, of the four genetic variants that were found to be predictive for acute esophagitis, three are part of signal transduction genes of cytokines and growth factors, whereas one is localized in a gene coding for a cell adhesion molecule. Although the encoded proteins are involved in radiation-induced reactions, studies linking polymorphisms in these genes to radiation toxicity have not been performed. Haploview analysis showed that the EGFR rs2302535 SNP is tightly linked with two nearby polymorphisms and that the TRAF3 rs1131877 SNP is strongly linked with a high number of intronic polymorphisms (mean maximum $r^{2}$ of 0.96 and 0.98 , respectively). A high degree of linkage $\left(r^{2}\right.$ $>0.8$ ) with other polymorphisms was not found for the $E N G$ and the ITGB2 SNPs. At present, the functional role of any of these polymorphisms is unknown. When a classical association analysis was performed on the dataset of the present study, none of the 332 considered SNPs were significantly associated with Grade $\geq 2$ acute esophagitis after correction for multiple testing with either Benjamini-Hochberg or Bonferroni tests. Only by omitting this correction, a number of polymorphisms, including the four retained in the prediction model, were significantly associated with esophagitis. The two TGFß1 SNPs (rs1800469/-509 and rs1800470/Leu10Pro), which were previously shown to be significantly associated with radiation-induced esophagitis or pneumonitis $(30,31)$, were not significantly associated with acute esophagitis in the present study and were also not retained in the model.

The final predictive model including 10 parameters estimates the risk of Grade $\geq 2$ acute esophagitis with $84.0 \%$ sensitivity and $75.3 \%$ specificity. By adding genetic data to the clinical and treatment parameters, the sensitivity of the model increased from $77 \%$ to $84 \%$. In our opinion, further progress is possible by genotyping a higher number of SNPs in a genome-wide approach. To evaluate the clinical usefulness of the biomarker, its predictive value was determined. With an incidence rate of $40 \%$ for Grade $\geq 2$ acute esophagitis as observed in the patient population of the present study, the positive predictive value of the biomarker is $69.4 \%$, and the negative predictive value is $87.4 \%$. In other words, 7 in 10 patients predicted to suffer from acute esophagitis will actually develop this toxicity and will 
benefit from therapy modification. Likewise, 9 in 10 patients will be correctly predicted as low-risk patients and will be suitable candidates for dose-escalation studies. In conclusion, the good performance of the model may be the basis of new prospective trials for treatment optimization in lung cancer patients treated with chemoradiation. Prospective validation in an independent patient cohort has started, to confirm this result.

\section{REFERENCES}

1. Jemal A, Siegel R, Xu J, et al. Cancer statistics, 2010. $C A$ Cancer J Clin 2010;60:277-300.

2. Auperin A, Le Pechoux C, Rolland E, et al. Meta-analysis of concomitant versus sequential radiochemotherapy in locally advanced non-small-cell lung cancer. J Clin Oncol 2010;28: 2181-2190.

3. De Ruysscher D, Faivre-Finn C, Nestle U, et al. European Organisation for Research and Treatment of Cancer recommendations for planning and delivery of high-dose, high-precision radiotherapy for lung cancer. J Clin Oncol 2010;28: 5301-5310.

4. Dehing-Oberije C, De Ruysscher D, Petit S, et al. Development, external validation and clinical usefulness of a practical prediction model for radiation-induced dysphagia in lung cancer patients. Radiother Oncol 2010;97:455-461.

5. Zhang ZC, Xu J, Li BS, et al. Clinical and dosimetric risk factors of acute esophagitis in patients treated with 3-dimensional conformal radiotherapy for non-small-cell lung cancer. Am J Clin Oncol 2010;33:271-275.

6. Rose J, Rodrigues G, Yaremko B, et al. Systematic review of dose-volume parameters in the prediction of esophagitis in thoracic radiotherapy. Radiother Oncol 2009;91:282-287.

7. Watkins JM, Wahlquist AE, Shirai K, et al. Factors associated with severe acute esophagitis from hyperfractionated radiotherapy with concurrent chemotherapy for limited-stage small-cell lung cancer. Int J Radiat Oncol Biol Phys 2009;74:1108-1113.

8. Rodriguez N, Algara M, Foro P, et al. Predictors of acute esophagitis in lung cancer patients treated with concurrent threedimensional conformal radiotherapy and chemotherapy. Int $J$ Radiat Oncol Biol Phys 2009;73:810-817.

9. Topkan E, Yavuz MN, Onal C, et al. Prevention of acute radiation-induced esophagitis with glutamine in non-small cell lung cancer patients treated with radiotherapy: Evaluation of clinical and dosimetric parameters. Lung Cancer 2009;63: 393-399.

10. De Ruysscher D, Dehing C, Bremer RH, et al. Maximal neutropenia during chemotherapy and radiotherapy is significantly associated with the development of acute radiation-induced dysphagia in lung cancer patients. Ann Oncol 2007;18:909916.

11. Wei X, Liu HH, Tucker SL, et al. Risk factors for acute esophagitis in non-small-cell lung cancer patients treated with concurrent chemotherapy and three-dimensional conformal radiotherapy. Int J Radiat Oncol Biol Phys 2006;66:100-107.

12. Takeda K, Nemoto K, Saito H, et al. Predictive factors for acute esophageal toxicity in thoracic radiotherapy. Tohoku J Exp Med 2006;208:299-306.

13. Ahn SJ, Kahn D, Zhou SM, et al. Dosimetric and clinical predictors for radiation-induced esophageal injury. Int J Radiat Oncol Biol Phys 2005;61:335-347.

14. Belderbos J, Heemsbergen W, Hoogeman M, et al. Acute esophageal toxicity in non-small cell lung cancer patients after high dose conformal radiotherapy. Radiother Oncol 2005;75: 157-164.

15. Chapet O, Kong FM, Lee JS, et al. Normal tissue complication probability modeling for acute esophagitis in patients treated with conformal radiation therapy for non-small cell lung cancer. Radiother Oncol 2005;77:176-181.

16. Kim TH, Cho KH, Pyo HR, et al. Dose-volumetric parameters of acute esophageal toxicity in patients with lung cancer treated with three-dimensional conformal radiotherapy. Int $J$ Radiat Oncol Biol Phys 2005;62:995-1002.

17. Patel AB, Edelman MJ, Kwok Y, et al. Predictors of acute esophagitis in patients with non-small-cell lung carcinoma treated with concurrent chemotherapy and hyperfractionated radiotherapy followed by surgery. Int J Radiat Oncol Biol Phys 2004;60:1106-1112.

18. Bradley J, Deasy JO, Bentzen S, et al. Dosimetric correlates for acute esophagitis in patients treated with radiotherapy for lung carcinoma. Int J Radiat Oncol Biol Phys 2004;58:1106-1113.

19. Singh AK, Lockett MA, Bradley JD. Predictors of radiationinduced esophageal toxicity in patients with non-small-cell lung cancer treated with three-dimensional conformal radiotherapy. Int J Radiat Oncol Biol Phys 2003;55:337-341.

20. Werner-Wasik M, Pequignot E, Leeper D, et al. Predictors of severe esophagitis include use of concurrent chemotherapy, but not the length of irradiated esophagus: A multivariate analysis of patients with lung cancer treated with nonoperative therapy. Int J Radiat Biol Oncol Phys 2000;48:689-696.

21. Maguire PD, Sibley GS, Zhou SM, et al. Clinical and dosimetric predictors of radiation-induced esophageal toxicity. Int $J$ Radiat Oncol Biol Phys 1999;45:97-103.

22. Andreassen $\mathrm{CN}$, Alsner J. Genetic variants and normal tissue toxicity after radiotherapy: A systematic review. Radiother Oncol 2009;92:299-309.

23. Alsbeih G, Al-Harbi N, Al-Hadyan K, et al. Association between normal tissue complications after radiotherapy and polymorphic variations in TGFB1 and XRCC1 genes. Radiat Res 2010;173:505-511.

24. Kerns SL, Ostrer H, Stock R, et al. Genome-wide association study to identify single nucleotide polymorphisms (SNPS) associated with the development of erectile dysfunction in African-American men after radiotherapy for prostate cancer. Int J Radiat Oncol Biol Phys 2010;78:1292-1300.

25. Mangoni M, Bisanzi S, Carozzi F, et al. Association between genetic polymorphisms in the XRCC1, XRCC3, XPD, GSTM1, GSTT1, MSH2, MLH1, MSH3, and MGMT genes and radiosensitivity in breast cancer patients. Int J Radiat Oncol Biol Phys. In press.

26. Fogarty GB, Muddle R, Sprung CN, et al. Unexpectedly severe acute radiotherapy side effects are associated with single nucleotide polymorphisms of the melanocortin-1 receptor. Int $J$ Radiat Oncol Biol Phys 2010;77:1486-1492.

27. Barnett GC, Coles CE, Burnet NG, et al. No association between SNPs regulating TGF-beta 1 secretion and late radiotherapy toxicity to the breast: Results from the RAPPER study. Radiother Oncol 2010;97:9-14.

28. Hildebrandt MA, Komaki R, Liao Z, et al. Genetic variants in inflammation-related genes are associated with radiationinduced toxicity following treatment for non-small cell lung cancer. PLoS One 2010;5:e12402.

29. Zhang L, Yang M, Bi N, et al. ATM polymorphisms are associated with risk of radiation-induced pneumonitis. Int J Radiat Biol Oncol Phys 2010;77:1360-1368.

30. Zhang L, Yang M, Bi N, et al. Association of TGF- $\beta 1$ and XPD polymorphisms with severe acute radiation-induced esophageal toxicity in locally advanced lung cancer patients treated with radiotherapy. Radiother Oncol 2010;97:19-25.

31. Yuan XL, Liao ZX, Liu ZS, et al. Single nucleotide polymorphism at rs1982073: T869C of the TGF beta 1 gene is 
associated with the risk of radiation pneumonitis in patients with non-small-cell lung cancer treated with definitive radiotherapy. J Clin Oncol 2009;27:3370-3378.

32. Werbrouck J, De Ruyck K, Duprez F, et al. Acute normal tissue reactions in head-and-neck patients treated with IMRT: Influence of dose and association with genetic polymorphisms in DNA DSB repair genes. Int J Radiat Oncol Biol Phys 2009; 73:1187-1195.

33. Cesaretti JA, Stock RG, Atencio DP, et al. A genetically determined dose-volume histogram predicts for rectal bleeding among patients treated with prostate brachytherapy. Int $J \mathrm{Ra}$ diat Oncol Biol Phys 2007;68:1410-1416.

34. Damaraju S, Murray D, Dufour J, et al. Association of DNA repair and steroid metabolism gene polymorphisms with clinical late toxicity in patients treated with conformal radiotherapy for prostate cancer. Clin Cancer Res 2006;12:2545-2554.

35. National Cancer Institute Cancer Therapy Evaluation Program. Protocol development. Available at: http://ctep.cancer.gov/ reporting/ctc.html. Accessed December 12, 2003.

36. Ovcharenko I, Nobrega MA, Loots GG, et al. ECR Browser: A tool for visualizing and accessing data from comparisons of multiple vertebrate genomes. Nucleic Acids Res 2004;32: W280-W286.

37. Tibshirani R. Regression shrinkage and selection via the lasso. $J$ R Stat Soc B 1996;58:267-288.

38. Robins JM, Wang N. Inference for imputation estimators. Biometrika 2000;87:113-124.

39. Rubin DB. Multiple imputation for nonresponse in surveys. New York: Wiley; 1987.

40. Rubin DB. Multiple imputation after $18+$ years. J Am Stat Assoc 1996;91:473-518.

41. Friedman J, Hastie T, Tibshirani R. Regularization paths for generalized linear models via coordinate descent. J Stat Softw 2010;33:1-22.
42. van Buuren S, Oudshoorn CGM. Multivariate imputation by chained equations. MICE V1.0 User's manual. TNO report 2000;PG/VGZ/00.038.

43. Werner-Wasik M, Yorke E, Deasy J, et al. Radiation dosevolume effects in the esophagus. Int J Radiat Oncol Biol Phys 2010;76:S86-S93.

44. Hardison RC. Conserved noncoding sequences are reliable guides to regulatory elements. Trends Genet 2000;16:369-372.

45. Mendelsohn J, Baselga J. Epidermal growth factor receptor targeting in cancer. Semin Oncol 2006;33:369-385.

46. McKibbin $\mathrm{T}$, Zhao W, Tagen M, et al. Epidermal growth factor receptor polymorphisms and risk for toxicity in paediatric patients treated with gefitinib. Eur J Cancer 2010;46: 2045-2051.

47. Giovannetti E, Zucali PA, Peters GJ, et al. Association of polymorphisms in AKT1 and EGFR with clinical outcome and toxicity in non-small cell lung cancer patients treated with gefitinib. Mol Cancer Ther 2010;9:581-593.

48. Bernabeu C, Blanco FJ, Langa C, et al. Involvement of the TGF-beta superfamily signalling pathway in hereditary haemorrhagic telangiectasia. J Appl Biomed 2010;8:169-177.

49. Scharpfenecker M, Floot B, Russell NS, et al. Endoglin haploinsufficiency reduces radiation-induced fibrosis and telangiectasia formation in mouse kidneys. Radiother Oncol 2009; 92:484-491.

50. Kruse JJCM, Floot BGJ, te Poele JAM, et al. Radiation-induced activation of TGF-beta signaling pathways in relation to vascular damage in mouse kidneys. Radiat Res 2009;171: 188-197.

51. Wang YY, Zhang P, Liu YF, et al. TRAF-mediated regulation of immune and inflammatory responses. Sci China Ser C 2010;53:159-168.

52. Baluna RG, Eng TY, Thomas CR. Adhesion molecules in radiotherapy. Radiat Res 2006;166:819-831. 